\title{
ĐÁNH GIÁ PHÁT TRIỂN THỂ CHÁT Ở BỆNH NHI SAU PHẪU THUẬT FONTAN TẠI TRUNG TÂM TIM MẠCH - BỆNH VIỆN E
}

\author{
Lưu Phưong Linh*, Đặng Thị Hải Vân**, Trần Đắc Đại*, Đỗ Anh Tiến*, Nguyễn Toàn Thắng*
}

\section{TÓM TẮT}

101 bệnh nhi được chẩn đoán tim bẩm sinh dạng một tâm thất đã phẫu thuật Fontan tại trung tâm tim mạch - Bệnh viện $\mathrm{E}$ từ $8 / 2012$ đến tháng 12/2018. Z-score của chiều cao, cân nặng trước phẫu thuật lần lượt là $-1,28 \pm 1,09$ và $-1,76 \pm 1,61$ (SD), được cải thiện rõ rệt sau phẫu thuật với Zscore của chiều cao, cân nặng theo tuổi tương ứng là $-0,87 \pm 1,06$ và $-0,85 \pm 1,14(\mathrm{SD}), \mathrm{p}<0,05$. Các yếu tố ảnh hưởng đến tăng trưởng của trẻ bao gồm phẫu thuật sớm trước 48 tháng tuổi, đặc điểm tâm thất hệ thống, tình trạng hở van nhĩ thất. Bệnh nhân sau phẫu thuật Fontan hầu hết đã bắt kịp tăng trưởng. Tuổi phẫu thuật và tình trạng hở van nhĩ thất có liên quan chẽ với sự tăng trưởng cân nặng và chiều cao của trẻ, trong khi dạng tâm thất hệ thống dường như không liên quan đến tăng trưởng sau phẫu thuật.

\section{SUMARRY}

We evaluated 101 patients who underwent the Fontan operation between 2012 and 2018. Postoperative height, and BMI for age z-score reached the $-0,87 \pm 1,06$ và $-0,85 \pm 1,14(\mathrm{SD})$, which were significantly better than preoperative values (the $-1,28 \pm 1,09$ and $-1,76 \pm 1,61(\mathrm{SD}), \mathrm{p}$ $<0,05$. Early surgical intervention before 4 yearold improved postoperative somatic development. The degree of atrioventricular valve regurgitation affected postoperative growth, meanwhile, the ventricular patterns were not associated with impaired somatic development. Long-term catchup growth can be observed in patients after the Fontan operation.

\section{I. ĐẶT VẤN ĐỀ}

Bệnh tim bẩm sinh dạng một tâm thất là một nhóm bệnh tim bẩm sinh phức tạp, bắt nguồn từ thời kỳ bào thai, đặc trưng với một buồng tống máu chức năng chịu trách nhiệm duy trì tuần hoàn hệ thống và tuần hoàn phổi. Do những sai khác về cấu trúc giải phẫu tương đối phức tạp cho nên không thể phẫu thuật bất thường dạng một tâm thất trở về cấu trúc bình thường mà cần đến một liệu trình 3 giai đoạn với phẫu thuật Fontan là thì sau cùng mới có thể giúp bệnh nhân cải thiện về thời gian và chất lượng cuộc sống. Tuy nhiên, phẫu thuật Fontan có nhiều biến chứng rất nặng nề, với đặc điểm suy giảm mọi chức năng theo thời gian, tình trạng giảm cung lượng tim dẫn đến chậm phát triển thể chất về lâu dài là không tránh khỏi.

Trải qua hơn 50 năm kể từ những trường hợp phẫu thuật Fontan đầu tiên, rất nhiều bệnh nhân sống sót với tuần hoàn Fontan đã đạt đến tuổi trưởng thành. Cùng với quá trình theo dõi liên tục, các bệnh nhân này là bằng chứng cho thấy sự cải thiện đáng kể về phát triển thể chất, khả năng gắng sức cũng như thời gian sống so với trước phẫu thuật và so với những đối tượng không có khả năng phẫu thuật.

Tại Việt Nam, phẫu thuật Fontan đã được tiến hành tại nhiều trung tâm. Trung tâm Tim mạch - Bệnh viện $\mathrm{E}$ bắt đầu tiến hành phẫu thuật Fontan từ năm 2012 với hơn 200 ca bệnh nhi mắc tim bẩm sinh dạng một tâm thất được phẫu thuật thành công. Tuy nhiên, những nghiên cứu về hiệu quả của phẫu thuật Fontan cũng như đánh giá sự phát triển thể chất cho nhóm bệnh nhân đặc biệt này vẫn còn bỏ ngỏ. Vì vậy chúng tôi thực hiện nghiên cứu này với mục tiêu: "Đánh giá sự phát triển thể chất và nhận xét một số yếu tố liên quan đến phát triển thể chất

*Trung tâm Tim mạch Bệnh viện E

** Bệnh Viện Nhi Trung Uong

Nguòi chịu trách nhiẹm khoa học: Luu Phuong Linh

Ngày nhận bài: 02/08/2020 - Ngày Cho Phép Đăng: 04/09/2020

Phản Biện Khoa học: PGS.TS. Đặng Ngọc Hùng PGS.TS. Đoàn Quốc Hưng 
của bệnh nhân sau phẫu thuật Fontan tại Trung tâm Tim mạch - Bệnh viện E”.

\section{II. ĐỐI TƯợNG VÀ PHƯƠNG PHÁP} NGHIÊN CÚU

\section{1. Đối tượng nghiên cứu}

- Đối tượng nghiên cứu: Bao gồm những bệnh nhi được chẩn đoán tim bẩm sinh dạng một tâm thất đã phẫu thuật Fontan tại trung tâm tim mạch - Bệnh viện $E$ từ 8/2012 đến tháng 12/2018

- Phương pháp chọn mẫu: Lấy mẫu theo phương pháp thuận tiện.

- Tiêu chuẩn lựa chọn: Bệnh nhân được chẩn đoán tim bẩm sinh dạng một tâm thất đã được phẫu thuật Fontan từ 8/2012 đến 12/2018 đến khám lại tại phòng khám trung tâm tim mạch - Bệnh viện $\mathrm{E}$ có đầy đủ hồ sơ bệnh án đáp ứng yêu cầu của nghiên cứu và người giám hộ đồng ý tham gia nghiên cứu.

- Tiêu chuẩn loại trừ: Bệnh nhân mắc các bệnh toàn thân, các rối loạn khác ảnh hưởng đến phát triển thể chất: hội chứng Down, suy thận mạn, suy giáp trạng bẩm sinh...

\subsection{Phương pháp nghiên cứu:}

- Thiết kế nghiên cứu: Nghiên cứu mô tả cắt ngang

- Tiến hành:

+ Tất cả các bệnh nhân được phẫu thuật Fontan tại trung tâm tim mạch - Bệnh viện $\mathrm{E}$ từ 8/2012 đến 12/2018 được thống kê lại, lấy hồ sơ bệnh án cũ thu thập các dữ liệu tại thời điểm trước phẫu thuật bao gồm: tuổi, bệnh tim nền, chiều cao, cân nặng, $\mathrm{SpO} 2$.

+ Gọi bệnh nhân lên khám lại: tiến hành đánh giá chiều cao, cân nặng, $\mathrm{SpO} 2$, các biến chứng muộn của phẫu thuật Fontan như tràn dịch màng phổi, mất protein ruột, rối loạn nhịp...

+ Chiều cao, cân nặng, BMI của trẻ được quy đổi ra Z-score theo công thức của CDC/NCHS 2000.

\subsection{Xử lý số liệu:}

Số liệu được thu thập và quản lý bằng phần mềm Excel và xử lý bằng các thuật toán thống kê trong y học với phần mềm SPSS 20.0.

\section{KẾT QUẢ:}

\section{1. Đặc điểm chung của nhóm nghiên cứu}

Bảng 1. Đặc điểm chung của nhóm nghiên cứu

\begin{tabular}{|l|l|c|c|}
\hline \multirow{2}{*}{ Giới } & Nặc điểm & Tần số (n) & Tỷ lệ (\%) \\
\cline { 2 - 4 } & Nữ & 61 & 60,4 \\
\hline \multirow{4}{*}{ Bệnh tim nền } & Dạng thất trái & 40 & 39,6 \\
\cline { 2 - 4 } & Dạng thất phải & 25 & 24,7 \\
\cline { 2 - 4 } & Dạng trung gian & 11 & 10,9 \\
\cline { 2 - 4 } & Dạng hai thất & 38 & 38,6 \\
\hline \multirow{3}{*}{ Tuổi phẫu thuật } & Trung bình \pm ĐC & \multicolumn{2}{|c|}{$61,9 \pm 34,4$ (tháng) } \\
\cline { 2 - 4 } & Trung vị & \multicolumn{2}{|c|}{49 (tháng) } \\
\cline { 2 - 4 } & Min - max & \multicolumn{2}{|c|}{$25-178$ (tháng) } \\
\hline Tuổi khám lại & Trung bình \pm ĐLC & $105,5 \pm 42,5$ (tháng) \\
\hline
\end{tabular}


Nhận xét:

Trong nghiên cứu của chúng tôi có 61 trẻ trai (chiếm 60,4\%) và 40 trẻ gái (chiếm 39,6\%).

Có 26 bệnh nhân có kiểu hình thất là dạng thất phải, chiếm $25,7 \%$. Các chẩn đoán bao gồm teo van hai lá, hội chứng heterotaxy, thông sàn nhĩ thất toàn bộ thể không cân xứng. Có 25 bệnh nhân có kiểu hình thất là dạng thất trái, bao gồm teo van ba lá, teo phổi lành vách liên thất, ebstein type C/D. 11 bệnh nhân có kiểu hình thất trung gian chiếm $10,9 \%$ và còn lại 38 bệnh nhân $(38,6 \%)$ có kiểu hình 2 thất.

Tuổi trung bình tại thời điểm phẫu thuật là $61 \pm 34,4$ tháng tuổi. Trẻ nhỏ nhất được phẫu thuật là 25 tháng và lớn nhất là 178 tháng. Tuổi trung bình tại thời điểm khám lại là 105,5 \pm 42,5 tháng tuổi.

\section{2. Đánh giá tăng trưởng sau phẫu thuật Fontan}

Bảng 2. Chỉ số chiều cao, cân nặng trước và sau phẫu thuật Fontan

\begin{tabular}{|l|c|c|c|}
\hline & $\mathrm{N}$ & Chiều cao (z-score) & Cân nặng (z-score) \\
\hline Trước phẫu thuật & 101 & $-1,28 \pm 1,09$ & $-1,76 \pm 1,61$ \\
\hline Sau phẫu thuật & 101 & $-0,87 \pm 1,06$ & $-0,85 \pm 1,14$ \\
\hline \multicolumn{1}{|c|}{} & & $p=0.0001^{*}$ & $p=0.0001^{*}$ \\
\hline
\end{tabular}

*T-test ghép cặp

Nhận xét: Z-score chiều cao và cân nặng theo tuổi của các bệnh nhân sau phẫu thuật cải thiện rõ rệt so với trước phẫu thuật. Sự khác biệt có ý nghĩa thống kê với độ tin cậy $99 \%$.

Bảng 3. Tình trạng dinh dưỡng của bệnh nhân trước và sau phẫu thuật theo chiều cao (phân loại dựa theo Z-score chiều cao theo tuổi - WHO 2006)

\begin{tabular}{|c|c|c|c|c|c|}
\hline \multirow{2}{*}{ Mức độ } & \multicolumn{2}{|c|}{ Trước phẫu thuật } & \multicolumn{2}{c|}{ Sau phẫu thuật } & \multirow{2}{*}{ p } \\
\cline { 2 - 5 } & $\mathbf{n}$ & $\mathbf{\%}$ & $\mathbf{n}$ & $\mathbf{\%}$ & \\
\hline SDD thể thấp còi nặng (<-3SD) & 5 & 4,9 & 3 & 3,0 & $0,32^{*}$ \\
\hline $\begin{array}{l}\text { SDD thể thấp còi vừa (-3SD đến } \\
\text {-2SD) }\end{array}$ & 17 & 16,8 & 9 & 8,9 & $0,03^{*}$ \\
\hline Bình thường (>2SD) & 79 & 78,2 & 89 & 88,1 & $0,01^{*}$ \\
\hline Tổng & 101 & 100 & 101 & 100 & \\
\hline
\end{tabular}

* Mc Nermar test

Nhận xét:

Trước phẫu thuật có $78,2 \%$ bệnh nhân có chiều cao nằm trong khoảng bình thường, sau phẫu thuật tăng lên là $88,1 \%$. Sự khác biệt có ý nghĩa thống kê, $\mathrm{p}<0,05$.

Suy dinh dưỡng thể thấp còi mức độ vừa trước phẫu thuật chiếm $17 \%$, sau phẫu thuật giảm còn $8,9 \%$, sự khác biệt có ý nghĩa thống kê p < 0,05. 


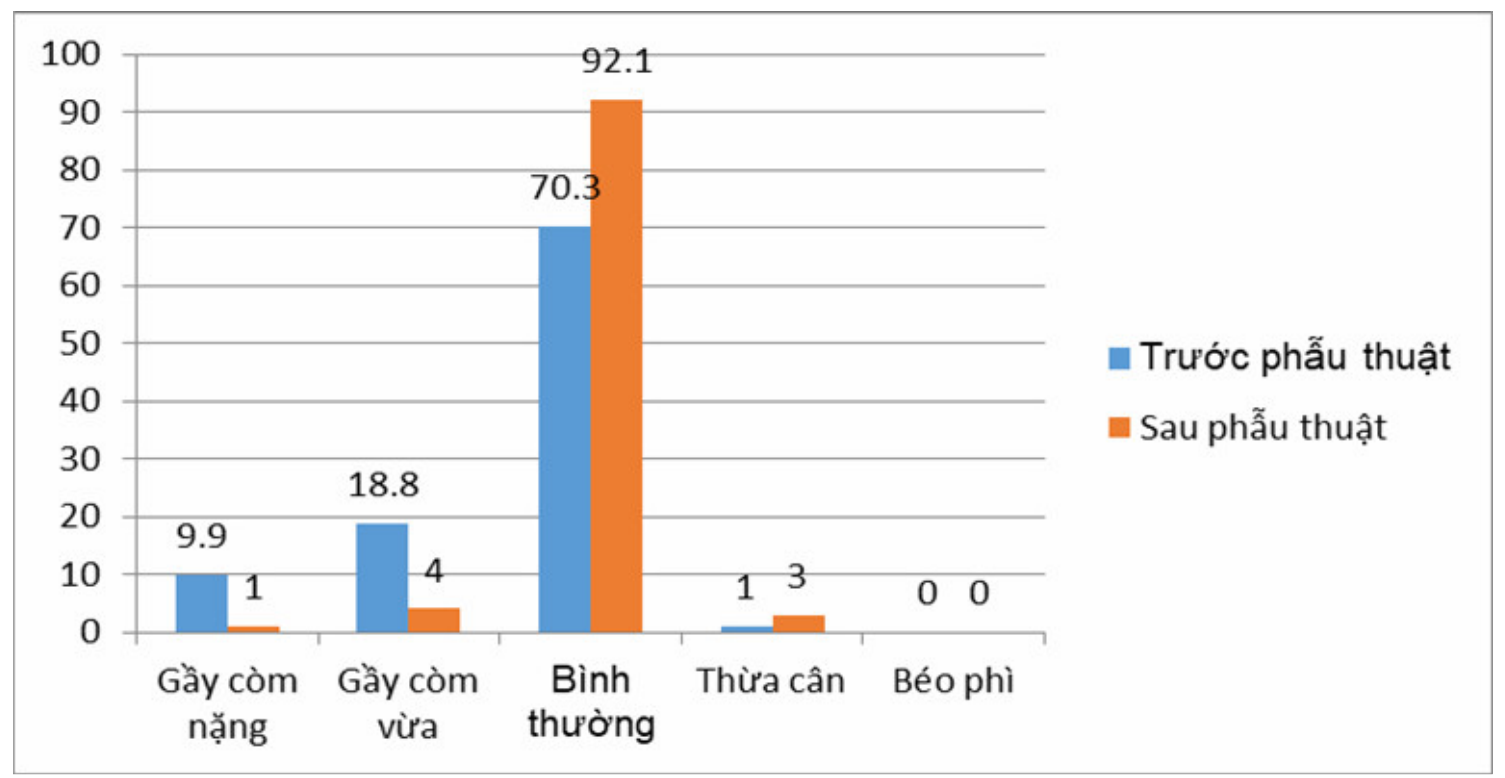

Biểu đồ 1: Tình trạng dinh dưỡng của bệnh nhân trước và sau phẫu thuật theo BMI (phân loại dựa theo Z-score BMI theo tuổi - WHO 2006).

Nhận xét: Trước phẫu thuật Fontan, có $9,9 \%$ bệnh nhân có tình trạng suy dinh dưỡng gầy còm mức độ nặng, $18,8 \%$ mức độ vừa. Sau phẫu thuật, con số này giảm xuống còn $1 \%$ và $4 \%$.

\subsection{Một số yếu tố liên quan đến phát triển thể chất}

Bảng 4. Ảnh hưởng của tuổi phẫu thuật với phát triển chiều cao, BMI sau phẫu thuật

\begin{tabular}{|l|c|c|c|}
\hline Tuổi phẫu thuật & $\mathrm{n}$ & $\begin{array}{c}\text { Chiều cao sau phẫu thuật } \\
(Z \text {-score })\end{array}$ & $\begin{array}{c}\text { Cân nặng sau phẫu } \\
\text { thuật (Z-score) }\end{array}$ \\
\hline$\leq 48$ tháng & 49 & $-0,49 \pm 1,08$ & $-0,4 \pm 1,04$ \\
\hline$>48$ tháng & 52 & $-1,22 \pm 0,92$ & $-1,2 \pm 1,1$ \\
\hline$p$ & $N=101$ & $p=0,0001^{*}$ & $p=0,0001^{*}$ \\
\hline
\end{tabular}

*Independent sample test

Nhận xét: Các bệnh nhân được phẫu thuật sớm trước 48 tháng tuổi có Z-score chiều cao và cân nặng theo tuổi tại thời điểm khám lại cao hơn so với nhóm trẻ được phẫu thuật sau 48 tháng. Sự khác biệt có ý nghĩa thống kê, p < 0,05.

Bảng 5. Ảnh hưởng của tình trạng hở van nhĩ thất với phát triển chiều cao, cân nặng sau phẫu thuật

\begin{tabular}{|c|c|c|c|}
\hline $\begin{array}{l}\text { Tình trạng hở van nhĩ } \\
\text { thất }\end{array}$ & $\mathrm{n}$ & $\begin{array}{c}\text { Chiều cao sau phẫu } \\
\text { thuật (Z-score) }\end{array}$ & $\begin{array}{c}\text { Cân nặng sau phẫu } \\
\text { thuật (Z-score) }\end{array}$ \\
\hline Không hở & 17 & $-0,69 \pm 0,98$ & $-0,64 \pm 1,03$ \\
\hline Hở nhẹ & 68 & $-0,7 \pm 1,03$ & $-0,64 \pm 1,11$ \\
\hline Hở vừa & 16 & $-1,75 \pm 0.83$ & $-1,97 \pm 0,69$ \\
\hline$\chi^{2, p}$ & $N=101$ & $p=0.001$ & $p=0,0001$ \\
\hline
\end{tabular}


Nhận xét: Sau phẫu thuật Fontan, tại thời điểm khám lại không có bệnh nhân hở van nhĩ thất mức độ nặng. Z-score chiều cao và cân nặng theo tuổi của ba nhóm không hở, hở nhẹ và hở vừa van nhĩ thất khác biệt có ý nghĩa thống kê, $\mathrm{p}<0,05$.

Bảng 6. Ảnh hưởng của dạng tâm thất với sự phát triển chiều cao, cân nặng sau phẫu thuật.

\begin{tabular}{|l|c|c|c|}
\hline Dạng tâm thất & $\mathrm{n}$ & $\begin{array}{c}\text { Chiều cao sau phẫu } \\
\text { thuật (Z-score) }\end{array}$ & $\begin{array}{c}\text { Cân nặng sau phẫu thuật } \\
\text { (Z-score) }\end{array}$ \\
\hline Dạng thất phải & 26 & $-0,97 \pm 1,1$ & $-0,89 \pm 1,07$ \\
\hline Dạng thất trái & 25 & $-0,85 \pm 0,83$ & $-0,75 \pm 1,16$ \\
\hline Dạng trung gian & 11 & $-1,29 \pm 1,34$ & $-1,33 \pm 1,65$ \\
\hline Dạng hai thất & 38 & $-0,69 \pm 1,07$ & $-0,75 \pm 1,02$ \\
\hline \multicolumn{1}{|c|}{$\chi 2, p$} & $N=101$ & $p=0,379$ & $p=0,496$ \\
\hline
\end{tabular}

Nhận xét: Không có sự khác biệt về Z-score chiều cao và cân nặng theo tuổi sau phẫu thuật Fontan giữa các bệnh nhân có kiểu hình thất khác nhau, $\mathrm{p}>0,05$.

\section{BÀN LUẬN}

Sự phát triển thể chất của trẻ em vẫn là các chỉ số cơ bản đánh giá hiệu quả điều trị suy tim sung huyết trong bệnh tim bẩm sinh. Trước khi có phẫu thuật Fontan, người ta đã chỉ ra rằng sự phát triển thể chất của trẻ em bị xanh tím mạn tính thường chậm hơn so với người khỏe mạnh [1].

Nghiên cứu của chúng tôi được tiến hành trên 101 bệnh nhi sau phẫu thuật Fontan, trong đó có 61 trẻ nam (chiếm 60,4\%) và 40 trẻ nữ (chiếm $39,6 \%$ ) (bảng 1). Z-score chiều cao và cân nặng theo tuổi trước phẫu thuật tương ứng lần lượt là $1,28 \pm 1,09(\mathrm{SD})$ và $-1,76 \pm 1,61(\mathrm{SD})$, trong khi các giá trị này sau phẫu thuật tương ứng lần lượt là $-0,87 \pm 1,06(\mathrm{SD})$ và $-0,85 \pm 1,14(\mathrm{SD})$ ở thời điểm khám lại, sự khác biệt có ý nghĩa thống kê với $\mathrm{p}<0,05$ (bảng 2). Kết quả này phù hợp với nhiều nghiên cứu trên thế giới chỉ ra rằng phần lớn trẻ sau phẫu thuật Fontan có sự tăng trưởng trội hơn so với trước phẫu thuật.

Theo nghiên cứu của Masamichi Ono trên đối tượng là 90 bệnh nhân sau phẫu thuật Fontan từ 1984 đến 2004, chỉ ra cân nặng, chiều cao, và chỉ số khối cơ thể (BMI) được cải thiện đáng kể so với trước phẫu thuật, sự khác biệt có ý nghĩa thống kê [2]. Theo S.Ovroutski và cộng sự, trung bình trẻ tăng $2,5 \mathrm{~kg}$ (từ 1,5 đến $5 \mathrm{~kg}$ ) mỗi năm sau phẫu thuật Fontan [1].

Các yếu tố ảnh hưởng đến phát triển thể chất sau phẫu thuật bao gồm tuổi phẫu thuật, tình trạng hở van sau phẫu thuật. Bệnh tim nền có ảnh hưởng không rõ rệt đến phát triển thể chất. Kết quả này phù hợp với nghiên cứu của các tác giả khác trên thế giới.

Trong nghiên cứu của chúng tôi, có 49 trẻ được tiến hành phẫu thuật trước 48 tháng tuổi. Nhóm này có $Z$-score chiều cao và cân nặng theo tuổi tại thời điểm khám lại lần lượt là $-0,49 \pm 1,08$ và $-0,4 \pm 1,04(\mathrm{SD})$ (bảng 4 ). 52 bệnh nhi còn lại được tiến hành phẫu thuật sau 48 tháng tuổi có Zscore chiều cao và cân nặng theo tuổi tại thời điểm khám lại là $-1,22 \pm 0,92$ và $-1,2 \pm 1,1(\mathrm{SD})$ (bảng 4), khác biệt có ý nghĩa thống kê so với nhóm được phẫu thuật trước 48 tháng tuổi. Theo S.Ovroutski và cộng sự, nhóm trẻ được phẫu thuật sớm (trước 4 tuổi), cân nặng trung bình theo bách phân vị bắt kịp cân nặng trẻ bình thường ở mức 50 bách phân vị (3-97\%) tương đương từ -2SD đến 2SD; trong khi nhóm trẻ phẫu thuật sau 4 tuổi, cân nặng trung vị ở mức 10 bách phân vị [1]. 
Theo Diller và cộng sự, chiều cao và cân nặng của trẻ sau phẫu thuật Fontan chủ yếu được cải thiện nhiều ở nhóm trẻ được phẫu thuật trước 5 tuổi [3]. Có thể do việc thiết lập sớm tuần hoàn Fontan cho phép cơ thể trẻ bắt kịp tốc độ tăng trưởng bình thường. Mặt khác, việc tăng chiều cao không đủ dẫn tới thấp lùn ở trẻ lớn có thể là do tuổi xương bị chậm, dường như bị ảnh hưởng bởi tình trạng thiếu oxy mạn tính ở giai đoạn trước phẫu thuật [4]. Tình trạng này được lý giải bởi nồng độ oxy máu thấp được cho là nguyên nhân dẫn đến giảm nồng độ hormon tăng trưởng IGF-1 (insulin like growth factor I), gây ra tình trạng chậm tăng trưởng ở trẻ mắc tim bẩm sinh có tím [5], [6]. Theo Dinleyici và cộng sự, nồng độ IGF-1 thấp hơn đáng kể ở nhóm trẻ mắc tim bẩm sinh có tím khi so sánh với nhóm tim bẩm sinh không tím và nhóm chứng $(\mathrm{p}<0.001)$ [6].

Tại thời điểm khám lại, trong số 101 bệnh nhân chúng tôi đánh giá trên siêu âm tim phát hiện 17 bệnh nhân không có hở van nhĩ thất, 68 bệnh nhân có hở van nhĩ thất nhẹ và 16 bệnh nhân có van hở vừa; không có bệnh nhân có tình trạng hở van mức độ nặng (bảng 5). Nhóm bệnh nhân có van nhĩ thất hở vừa có $Z$-score chiều cao và cân nặng theo tuổi tại thời điểm khám lại là $1,75 \pm 0.83$ và $-1,97 \pm 0,69(\mathrm{SD})$ (bảng 5 ). Theo tác giả Anderson và cộng sự, tỉ lệ hở van nhĩ thất trong quá trình theo dõi trung dài hạn sau phẫu thuật Fontan lần lượt là $26 \%, 55 \%, 19 \%$ và $<1 \%$ cho các nhóm không hở, hở nhẹ, hở vừa và hở nặng [7]. Phát triển thể chất của bệnh nhân bị ảnh hưởng lớn bởi tình trạng hở van tim do quá tải thể tích và giãn các buồn tim, gián tiếp gây giảm cung lượng tuần hoàn. Ở các bệnh nhân sau phẫu thuật Fontan, tình trạng hở van nhĩ thất nặng có liên quan chặt chẽ với sự suy giảm chức năng thất, dẫn đến suy chức năng đa cơ quan, qua đó ảnh hưởng nghiêm trọng đến tăng trưởng.

Về ảnh hưởng của kiểu hình thất đến sự phát triển thể chất, nghiên cứu của chúng tôi không tìm thấy sự khác biệt giữa các nhóm bệnh nhân có kiểu hình thất là dạng thất phải, thất trái, trung gian và dạng hai thất, $\mathrm{p}>0.05$. Các nghiên cứu trước đây chỉ ra rằng, những bệnh nhân tim một thất dạng thất phải thường có chức năng tim thấp hơn, dẫn đến giảm khả năng gắng sức cũng như tốc độ tăng trưởng. Theo tác giả Anderson và cộng sự, phân số tống máu (EF z-score) của bệnh nhân có thất chung dạng thất phải là $-1,4 \pm 2,3$, thất trái là $-0,6 \pm 1,8(\mathrm{p}<0,001)$; tình trạng hở van nhĩ thất cũng thường nặng hơn ở kiểu hình thất phải [7]. Tuy nhiên, nhiều nghiên cứu khác chỉ ra, kiểu hình thất dạng thất phải không phải là yếu tố nguy cơ làm giảm tốc độ tăng trưởng của trẻ sau phẫu thuật Fontan [1] [2]. Trên một báo cáo thống kê đa trung tâm, hội chứng Heterotaxy mặc dù là yếu tố nguy cơ gây ra rất nhiều các biến chứng khác nhau ở cả giai đoạn sớm và muộn - nhưng không có liên quan với tình trạng suy giảm thể chất [8].

\section{KẾT LUẬN}

Nghiên cứu 101 bệnh nhi sau phẫu thuật Fontan tại Trung tâm Tim Mạch, bệnh viện E chúng tôi rút ra một số kết luận sau:

- Cân nặng và chiều cao của bệnh nhân được cải thiện đáng kể sau phẫu thuật, tương ứng lần lượt là $-0,87 \pm 1,06(\mathrm{SD})$ và $-0,35 \pm 1,02(\mathrm{SD})$

- Các yếu tố ảnh hưởng rõ rệt đến sự tăng trưởng của bệnh nhân sau phẫu thuật Fontan bao gồm tuổi phẫu thuật sớm (trước 4 tuổi) và tình trạng hở van nhĩ thất.

- Bệnh tim nền của trẻ dường như không ảnh hưởng đến sự phát triển thể chất của trẻ sau phẫu thuật.

\section{TÀI LIỆU THAM KHẢO}

1. Lange PE, Ovroutski S, Stiller B et al (2004). Comparison of somatic development and status of conduit after extracardiac Fontan operation in young and older children. Eur $J$ Cardiothorac Surg, 26:1073-9.

2. Boethig $\mathrm{D}$, Goerler $\mathrm{H}$, Ono $\mathrm{M}$ et al (2007). Somatic development long after the 
Fontan operation: Factors influencing catch-up growth. J Thorac Cardiovasc Surg, 134:11991206.e2.

3. Diller GP, Dimopoulos K, Giardini A et al (2010). Predictors of morbidity and mortality in contemporary Fontan patients: results from a multicenter study including cardiopulmonary exercise testing in 321 patients. Eur Heart J, 31: 3073-83.

4. Danilowicz DA (1973). Delay in Bone Age in Children with Cyanotic Congenital Heart Disease. Radiology, 108:655-8.

5. Akçoral A, Dündar B, Saylam G et al (2000). Chronic hypoxemia leads to reduced serum IGF-I levels in cyanotic congenital heart disease. J Pediatr Endocrinol Metab JPEM, 13:431-6.
6. Buyukkaragoz B, Dinleyici EC, Kilic Z et al (2007). Serum IGF-1, IGFBP-3 and growth hormone levels in children with congenital heart disease: relationship with nutritional status, cyanosis and left ventricular functions. Neuro Endocrinol Lett, 28:279-83.

7. Anderson PAW, Mahony L, Sleeper LA et al (2008). Contemporary outcomes after the Fontan procedure: a Pediatric Heart Network multicenter study. J Am Coll Cardiol, 52:85-98.

8. Atz AM, Cohen MS, Sleeper LA et al (2007). Functional state of patients with heterotaxy syndrome following the Fontan operation. Cardiol Young, 17 Suppl, 2: 44-53.

9. Bush DM, Cohen MI, Ferry RJ et al (2000). Somatic growth failure after the Fontan operation. Cardiol Young, 10:447-57. 